\title{
Incidence of heterotopic ossification after implantation of interspinous process devices
}

\author{
NaI-Feng Tian, M.D., ${ }^{1}$ Ai-Min Wu, M.D., ${ }^{1}$ Li-Jun Wu, M.D.,${ }^{2}$ Xin-Lei Wu, M.S., ${ }^{2}$ \\ YaO-Sen Wu, M.D., ${ }^{3}$ XiaO-Lei Zhang, M.D., ${ }^{1}$ HuA-Zi Xu, M.D., ${ }^{1}$ \\ AND Yong-Long CHI, M.D. ${ }^{1}$ \\ ${ }^{1}$ Zhejiang Spine Research Center, Department of Orthopaedic Surgery, Second Affiliated Hospital of Wenzhou \\ Medical College; ${ }^{2}$ Institute of Digitized Medicine, Wenzhou Medical College, Wenzhou, Zhejiang, China; \\ and ${ }^{3}$ Department of Orthopaedics, Second Affiliated Hospital, School of Medicine, Zhejiang University, \\ Hangzhou, Zhejiang, China
}

\begin{abstract}
Object. This study aimed to investigate the incidence rate of heterotopic ossification $(\mathrm{HO})$ after implantation of Coflex interspinous devices. Possible risk factors associated with $\mathrm{HO}$ were evaluated.

Methods. The authors retrospectively analyzed patients who had undergone single-level (L4-5) implantation of a Coflex device for the treatment of lumbar spinal stenosis. Patient data recorded were age, sex, height, weight, body mass index, smoking habits, and surgical time. Heterotopic ossification was identified through lumbar anteroposterior and lateral view radiographs. The authors developed a simple classification for defining $\mathrm{HO}$ and compared HO-positive and HO-negative cases to identify possible risk factors.

Results. Among 32 patients with follow-up times of 24-57 months, $\mathrm{HO}$ was detectable in 26 (81.2\%). Among these 26 patients, $\mathrm{HO}$ was in the lateral space of the spinous process but not in the interspinous space in 8 , $\mathrm{HO}$ was in the interspinous space but did not bridge the adjacent spinous process in 16, and interspinous fusion occurred at the level of the device in 2. Occurrence of $\mathrm{HO}$ was not associated with patient age, sex, height, weight, body mass index, smoking habits, or surgical time.

Conclusions. A high incidence of $\mathrm{HO}$ has been detected after implantation of Coflex devices. Clinicians should be aware of this possible outcome, and more studies should be conducted to clarify the clinical effects of $\mathrm{HO}$. (http://thejns.org/doi/abs/10.3171/2013.3.FOCUS12406)
\end{abstract}

\section{KeY WoRdS - interspinous process device • heterotopic ossification • lumbar spine}

$\mathrm{O}$ VER the past several years, ISP devices have gained popularity, although they are still in the early stage of clinical use. . $^{3,4,6,8,14,18,19,21}$ They provide an alternative to arthrodesis for patients with degenerative lumbar disease. Several ISP devices are currently available, and they can be categorized as static or dynamic. ${ }^{3}$ Biomechanical studies have shown that ISP implants strongly stabilize and reduce intradiscal pressure during extension but that they have little effect during flexion, lateral bending, and axial rotation. ${ }^{8,19}$ Because ISP devices provide motion-preserving stabilization, they can decrease the risk for adjacent-segment disease.

Heterotopic ossification is the presence of bone in soft tissue where bone normally does not exist. ${ }^{16}$ It frequently occurs in patients with CNS disorders, multiple injuries, joint arthroplasty, and/or burns. ${ }^{27,16}$ Recently, a high prevalence of heterotopic bone formation has also been reported for patients who have undergone spinal

Abbreviations used in this paper: $\mathrm{HO}=$ heterotopic ossification; ISP $=$ interspinous process. total disc arthroplasty. ${ }^{5,10,12,15,17,20}$ Heterotopic ossification can negatively affect patients' daily activity if it decreases mobility of the joints and implants. ${ }^{16}$ The incidence and clinical significance of $\mathrm{HO}$ after implantation of ISP devices have yet to be clarified. Miller et al. ${ }^{13}$ noted the phenomenon of reactive osteophytes growing bilaterally along the interface of the spinous process and X-STOP device in a revision surgery. Maida et al. $^{11}$ reported the first case of $\mathrm{HO}$ after implantation of a Coflex device; the patient had undergone a revision surgery for recurrence of neurogenic claudication caused by abnormal ossification. ${ }^{11}$ In this study, we aimed to investigate the prevalence of HO after placement of Coflex ISP devices (Paradigm Spine) and to evaluate possible risk factors associated with the occurrence of $\mathrm{HO}$.

\section{Methods}

We retrospectively reviewed the medical records of patients who had undergone implantation of a Coflex device for the treatment of lumbar spinal stenosis at the 
Second Affiliated Hospital of Wenzhou Medical College from December 2007 through March 2010. For these patients, conservative treatment for at least 3 months had failed. The diagnosis was confirmed through preoperative neurological examination and image assessment including static (anteroposterior and lateral) and dynamic (flexion and extension) radiography, CT, and MRI. We included patients in whom device placement involved a single level (L4-5) and who had completed follow-up visits for at least 2 years. Inclusion and exclusion criteria are shown in Table 1.

The study was approved by the hospital institutional review board. All patients gave informed content. After induction of general anesthesia, patients were placed prone. The operation included decompression and an interspinous dynamic fixation. The decompressive surgery was conducted through a laminotomy, resection of the thickened ligamentum flavum, and an undercutting facetectomy. In 3 patients, concomitant herniated disc was removed. After the interspinous ligament was excised, an interspinous implant of proper size was inserted into the prepared space. The clips around the spinous processes were tightened. Perioperative NSAIDs, if not contraindicated, were routinely prescribed for 2-4 weeks. Postoperatively, patients were asked to return to undergo standard anteroposterior and lateral flexion-extension plain radiographs at approximately 3, 6, and 12 months and every year thereafter.

We developed the following simple classification of $\mathrm{HO}$ for this study: Grade 0, no HO; Grade 1, HO in the lateral space of the spinous process but not in the interspinous space; Grade 2, HO in the interspinous space (regardless whether Grade $1 \mathrm{HO}$ is present) but not bridged across the adjacent spinous process; and Grade 3, interspinous fusion. Anteroposterior radiographs were used to identify $\mathrm{HO}$ in the lateral space of the spinous process (Fig. 1). Lateral radiographs were used to identify $\mathrm{HO}$ in the interspinous space (Fig. 2). According to occurrence of $\mathrm{HO}$, patients were divided into $\mathrm{HO}$-positive and $\mathrm{HO}$ negative groups. Continuous variables were compared by using an independent-samples t-test, and categorical vari-

\section{TABLE 1: Summary of study inclusion and exclusion criteria}

\begin{tabular}{l}
\hline \multicolumn{1}{c}{ Criteria for Inclusion \& Exclusion } \\
\hline inclusion \\
clinical symptoms of leg or buttock pain w/ or w/o back pain \\
CT \& MRI confirmation of lumbar stenosis \\
failed conservative treatment $\geq 3$ mos \\
single level involved (L4-5) \\
age $\geq 40$ yrs \\
exclusion \\
lumbar spondylolisthesis \\
radiographic lumbar spinal instability \\
spinal fracture, infection, deformity, tumor, or inflammatory spondy- \\
lopathy \\
concomitant serious diseases \\
previous back surgery
\end{tabular}

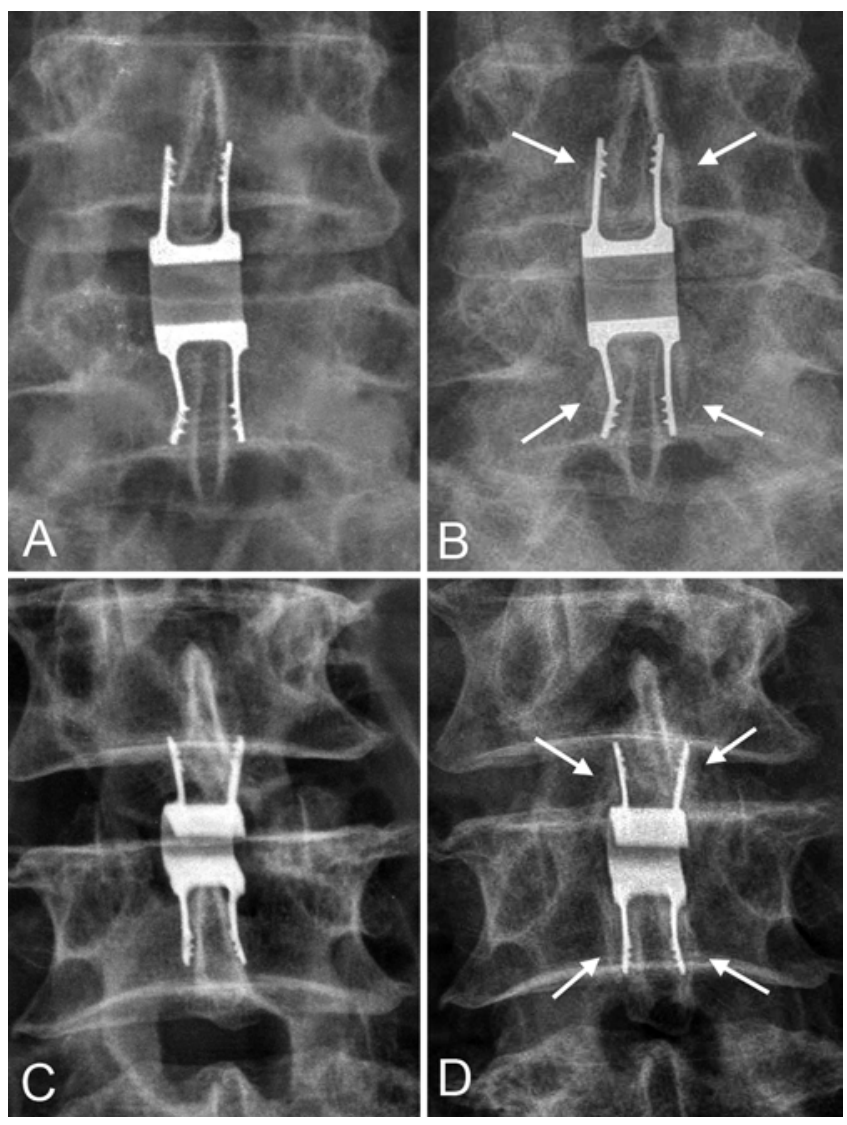

FIG. 1. Radiographs of 2 patients, anteroposterior views. Arrows indicate $\mathrm{HO}$ in the lateral space of the spinous process. A and C: Images obtained immediately after surgery. B and D: Images obtained at the final follow-up visit.

ables were analyzed by using the chi-square test. The level of significance was set at $\mathrm{p}<0.05$.

\section{Results}

A total of 32 patients were included in this study: 13 women and 19 men. The mean age of all patients was 60.3 years (range 45-75 years). Follow-up visits ranged from 24 to 57 months. One year after surgery, follow-up visits became irregular for most patients because their symptoms had substantially improved. Only one patient was not satisfied with the surgical outcome. No patients needed revision or removal of the implants; no fractures or loosening of the implant occurred.

Among the 32 patients, $\mathrm{HO}$ grades were as follows: Grade 0 for 6 patients (18.8\%), Grade 1 for 8 patients (25\%), Grade 2 for 16 patients (50\%), and Grade 3 for 2 patients (6.3\%) (Figs. 3 and 4). Comparisons between HOpositive and HO-negative groups revealed that age, sex, height, weight, body mass index, smoking habits, and surgical time were not associated with the occurrence of $\mathrm{HO}$ (Table 2). As follow-up time increased, the grade of $\mathrm{HO}$ also increased. Among 9 patients who were followed up for more than 3 years, Grade 2 or $3 \mathrm{HO}$ was detected in all 9. 

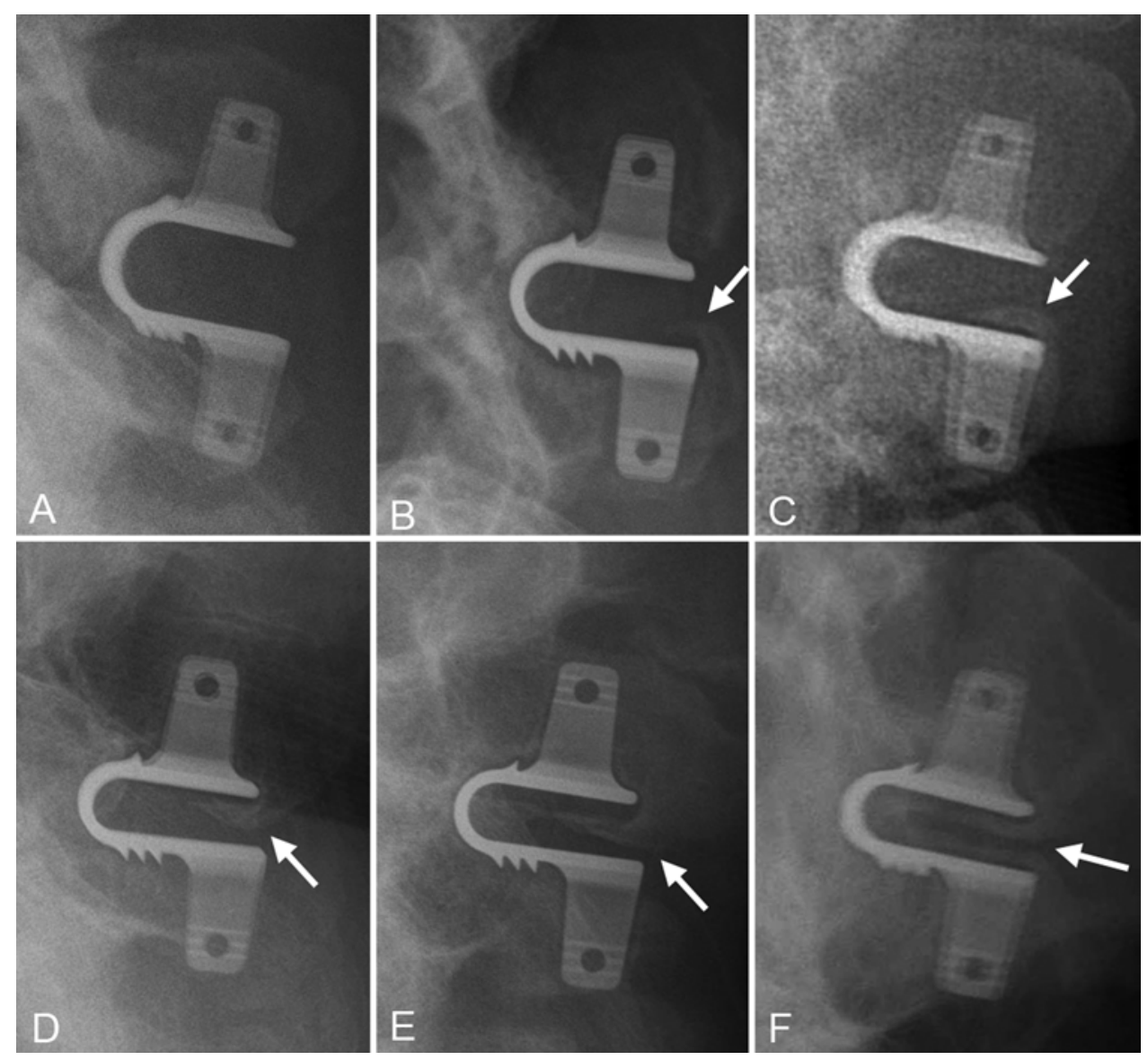

FIG. 2. Radiographs of 6 patients, lateral views.

A: No HO. B-F: Various forms of $\mathrm{HO}$ (arrows) in the interspinous space.

\section{Discussion}

The concept of ISP distraction implants is not new; it was originated in the 1950s by Knowles. ${ }^{9}$ However, the early device fell into disuse because of its frequent loosening and migration. In the past 2 decades, a new generation of ISP devices has been developed. ${ }^{3,6}$ Although ISP devices vary in design, their common aim is to limit motion during extension but allow some degree of motion in other directions. ${ }^{8}$ Through interspinous distraction, the devices could unload the facet joints, restore foraminal height, and lower intradiscal pressure. ${ }^{19}$ The proposed indications for their use are wide, including degenerative spinal stenosis, low-grade degenerative spondylolisthesis, discogenic lowback pain, facet syndrome, and disc herniations. ${ }^{3,4,6,8,14,19,21}$ Recent clinical evidence has suggested that lumbar ISP spacers might be beneficial for a select group of patients. ${ }^{8}$ Furthermore, radiological and biomechanical evidence has shown beneficial effects, such as significantly increased neural foramen and spinal canal dimensions, lowered intradiscal pressure at the level of the device, and decreased pressure at the facets but no alteration of kinematics at adjacent levels. ${ }^{8}, 19$ However, ISP devices are still in the early stage of clinical use; some potential complications may be unforeseen.

Heterotopic ossification is a well-known complication after arthroplasty of large joints. ${ }^{1,2,7,16}$ In the spinal region, $\mathrm{HO}$ is gaining attention because of its high incidence af- ter total disc arthroplasty. $5,10,12,15,17,20$ The incidence of $\mathrm{HO}$ after total cervical disc arthroplasty ranges between $17.8 \%$ and $78.5 \% .^{5,10,20}$ The incidence of HO after total lumbar disc arthroplasty ranges from $1.4 \%$ to $15.2 \% .^{12,15,17}$ For the case series reported here, the incidence of $\mathrm{HO}$ after dynamic interspinous stabilization was $81.2 \%$; follow-up times ranged from 24 to 54 months; and for half the patients, $\mathrm{HO}$ occurred in the interspinous space. In 2 patients, the level at which the device was placed was fused. Although risk factors for development of $\mathrm{HO}$ have been reported, ${ }^{7,10,16}$ we found several factors that were not associated with HO: patient age, sex, height, weight, body mass index, smoking habits, and surgical time. Perhaps this variation is the result of different types of surgery and the small sample size in our study.

The exact mechanisms of heterotopic bone formation remain unclear. Methods such as radiotherapy and perioperative use of NSAIDs have been proven to prevent $\mathrm{HO}$ after total hip arthroplasty. ${ }^{1,7,16,17}$ Because radiotherapy can injure the spinal cord, the use of NSAIDs would be more appropriate for patients after spinal surgery.

The normal spinous process is generally under tension from the interspinous ligament. After implantation of ISP devices, this tension environment is altered, which causes consistent compression to the spinous process. One negative result is fracture of the spinous process. ${ }^{4}$ Another effect, such as HO, might be found at a long-term follow- 

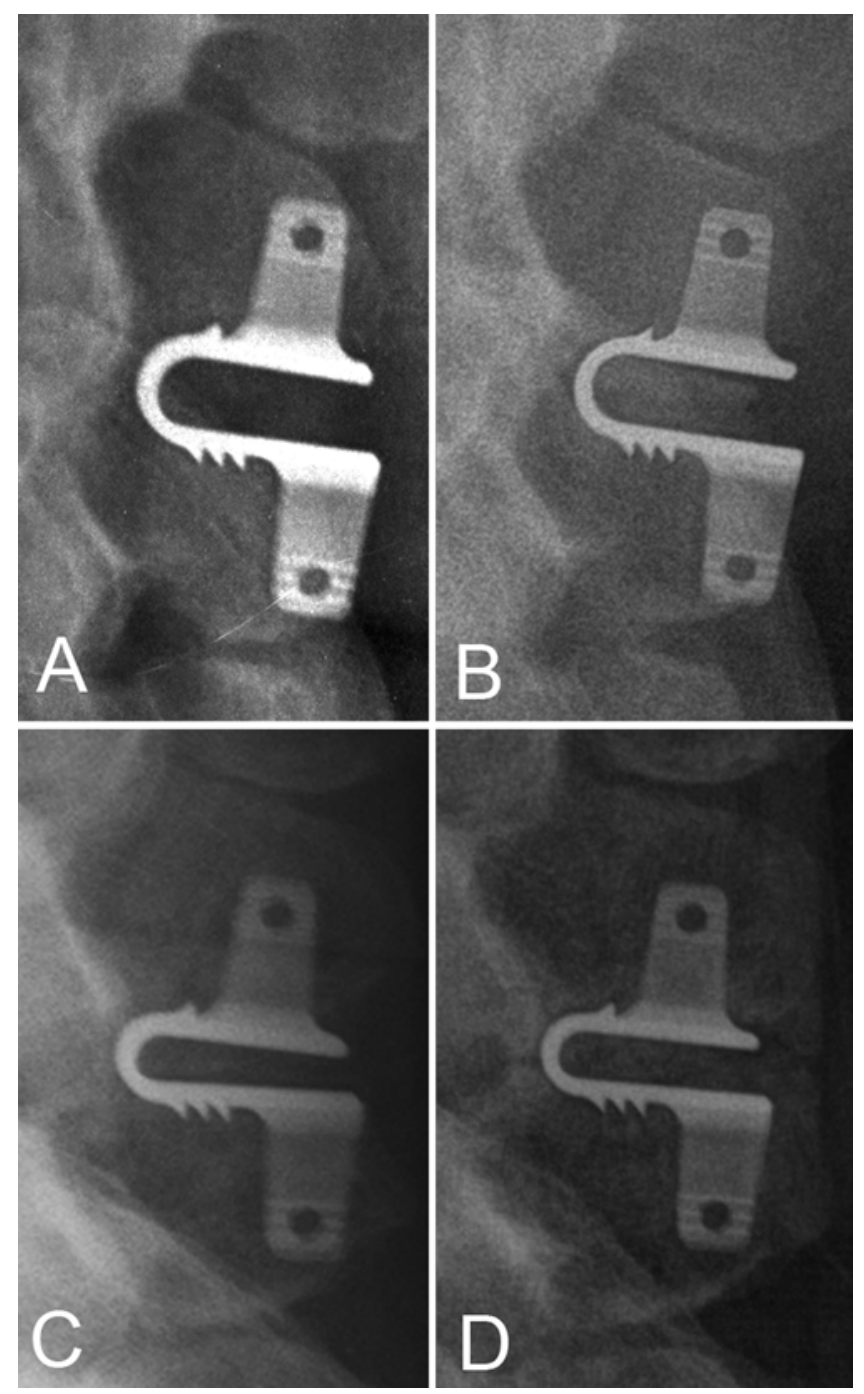

FIG. 3. Radiographs of 2 patients, lateral views. A and C: No HO seen immediately after surgery. $\mathbf{B}$ and $\mathbf{D}$ : Interspinous fusion at the final follow-up visit.

up visit. ${ }^{11}$ The clinical significance of $\mathrm{HO}$ after placement of ISP devices is unclear. Large osteophytes could intrude into the spinal canal, which might injure the neural structure. In a case report by Maida et al., ${ }^{11}$ the dural sac was compressed by the heterotopic bone, which resulted in re-
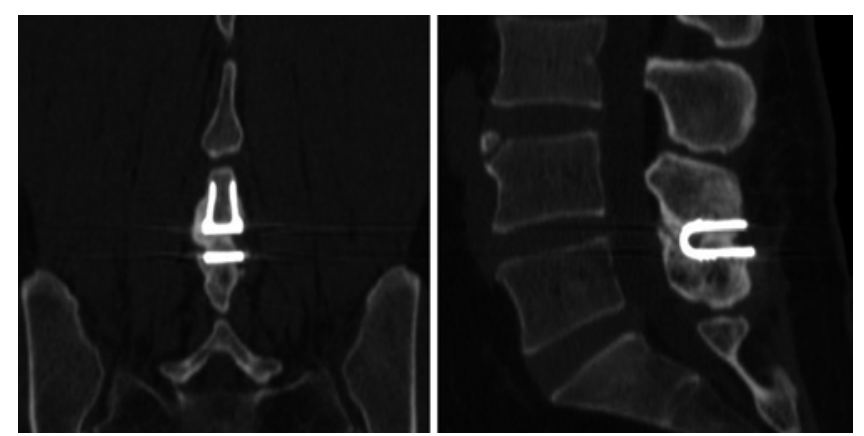

FIG. 4. CT images of 1 patient, showing interspinous fusion on coronal (left) and sagittal (right) scans.
TABLE 2: Baseline comparisons between HO-negative and HO-positive patients*

\begin{tabular}{lccc}
\hline \multicolumn{1}{c}{ Characteristic } & HO Negative & HO Positive & $p$ Value \\
\hline mean age $(\mathrm{yrs})$ & $56.0 \pm 5.8$ & $61.3 \pm 9.7$ & 0.208 \\
sex ratio $(\mathrm{M} / \mathrm{F})$ & $4: 2$ & $14: 12$ & 0.672 \\
mean weight $(\mathrm{kg})$ & $66.3 \pm 11.3$ & $63.9 \pm 7.8$ & 0.535 \\
mean height $(\mathrm{cm})$ & $167.7 \pm 5.5$ & $166.1 \pm 6.6$ & 0.591 \\
mean body mass index $\left(\mathrm{kg} / \mathrm{m}^{2}\right)$ & $23.5 \pm 3.0$ & $23.1 \pm 1.9$ & 0.715 \\
smoker/nonsmoker ratio & $1: 5$ & $6: 20$ & 1.000 \\
mean operative time (mins) & $100.8 \pm 13.2$ & $111.9 \pm 20.1$ & 0.210 \\
\hline
\end{tabular}

* Mean values presented \pm SD.

current symptoms of lumbar stenosis. However, such an outcome is very rare; only 1 case has been reported. In the case series reported here, no patients experienced recurrence of symptoms resulting from HO. Furthermore, $\mathrm{HO}$ around a dynamic interspinous device could hamper motion. This effect was obvious when the interspinous device was fused. Therefore, limited motion might be a potential complication found during mid-term and long-term follow-up examinations because the fused device did not work as initially intended. One question is whether $\mathrm{HO}$ is more likely to be produced by the Coflex device than by other ISP devices. Because the metal clips of the Coflex device are fixed around the spinous process, the resulting consistent stress at the interface between the bone and implant might stimulate growth of heterotopic bone. Furthermore, the U-shaped Coflex implant is hollow. Heterotopic ossification could easily grow into the empty space. This hollow core could be one thing that the manufacturer could modify on the device. However, HO around the Coflex device is not necessarily bad. Theoretically, it could enhance the dynamic stabilization at the level of the device. Therefore, we might use the device, rather than lumbar fusion, to treat degenerative lumbar instability or instability caused by decompressive surgery.

Our study has several limitations. First, it was a retrospective study in which the number of enrolled patients was small. Follow-up times were not the same among the patients. Second, detecting HO through radiographs might not be precise. Projection of small facets and iliac crest might interfere with detection of small heterotopic bone. Examination of CT scans might be a more accurate method. Third, the clinical significance of $\mathrm{HO}$ after implantation of ISP devices requires further investigation. Because several outcome measures, such as visual analog scale or Oswestry Disability Index scores, were not recorded prospectively, we still do not know whether the occurrence of $\mathrm{HO}$ would affect clinical outcomes. Therefore, to clarify the true prevalence and clinical effects of HO after implantation of ISP devices, additional studies with large sample sizes and long-term follow-up should be conducted.

\section{Conclusions}

To our knowledge, this case series is the first to de- 


\section{Heterotopic ossification after dynamic interspinous fixation}

scribe the forms of $\mathrm{HO}$ that occur after implantation of ISP devices. The incidence of HO during a 24- to 57-month follow-up period was high. Interspinous fusion occurred in 2 patients. Because the fused device did not work as initially intended, limited motion might be a potential complication found during mid-term and long-term follow-up visits. Therefore, the device manufacturer and the surgeons should be aware of the occurrence of $\mathrm{HO}$ after implantation of an ISP device. Further studies are needed to explore the clinical significance.

\section{Disclosure}

The authors report no conflict of interest concerning the materials or methods used in this study or the findings specified in this paper.

Author contributions to the study and manuscript preparation include the following. Conception and design: Xu, Tian. Acquisition of data: A Wu, X Wu. Analysis and interpretation of data: A Wu, X $\mathrm{Wu}$. Drafting the article: Tian, Y Wu. Critically revising the article: $\mathrm{Xu}, \mathrm{L} \mathrm{Wu}$, Chi. Reviewed submitted version of manuscript: $\mathrm{Xu}$. Approved the final version of the manuscript on behalf of all authors: Xu. Statistical analysis: Zhang. Administrative/technical/material support: $\mathrm{Xu}$, Chi. Study supervision: $\mathrm{Xu}$.

\section{References}

1. Bek D, Beksaç B, Della Valle AG, Sculco TP, Salvati EA: Aspirin decreases the prevalence and severity of heterotopic ossification after 1-stage bilateral total hip arthroplasty for osteoarthrosis. J Arthroplasty 24:226-232, 2009

2. Board TN, Karva A, Board RE, Gambhir AK, Porter ML: The prophylaxis and treatment of heterotopic ossification following lower limb arthroplasty. J Bone Joint Surg Br 89:434-440, 2007

3. Bono CM, Vaccaro AR: Interspinous process devices in the lumbar spine. J Spinal Disord Tech 20:255-261, 2007

4. Bowers C, Amini A, Dailey AT, Schmidt MH: Dynamic interspinous process stabilization: review of complications associated with the X-Stop device. Neurosurg Focus 28(6):E8, 2010

5. Chen J, Wang X, Bai W, Shen X, Yuan W: Prevalence of heterotopic ossification after cervical total disc arthroplasty: a meta-analysis. Eur Spine J 21:674-680, 2012

6. Christie SD, Song JK, Fessler RG: Dynamic interspinous process technology. Spine (Phila Pa 1976) 30 (16 Suppl):S73S78, 2005

7. Iorio R, Healy WL: Heterotopic ossification after hip and knee arthroplasty: risk factors, prevention, and treatment. J Am Acad Orthop Surg 10:409-416, 2002

8. Kabir SM, Gupta SR, Casey AT: Lumbar interspinous spacers: a systematic review of clinical and biomechanical evidence. Spine (Phila Pa 1976) 35:E1499-E1506, 2010
9. Knowles FL: The Knowles vertebral support operation. J Iowa State Med Soc 48:551-554, 1958

10. Leung C, Casey AT, Goffin J, Kehr P, Liebig K, Lind B, et al: Clinical significance of heterotopic ossification in cervical disc replacement: a prospective multicenter clinical trial. Neurosurgery 57:759-763, 2005

11. Maida G, Marcati E, Sarubbo S: Heterotopic ossification in vertebral interlaminar/interspinous instrumentation: report of a case. Case Rep Surg 2012:970642, 2012

12. McAfee PC, Cunningham BW, Devine J, Williams E, Yu-Yahiro J: Classification of heterotopic ossification $(\mathrm{HO})$ in artificial disk replacement. J Spinal Disord Tech 16:384-389, 2003

13. Miller JD, Miller MC, Lucas MG: Erosion of the spinous process: a potential cause of interspinous process spacer failure. Report of 2 cases. J Neurosurg Spine 12:210-213, 2010

14. Moojen WA, Arts MP, Bartels RH, Jacobs WC, Peul WC: Effectiveness of interspinous implant surgery in patients with intermittent neurogenic claudication: a systematic review and meta-analysis. Eur Spine J 20:1596-1606, 2011

15. Park SJ, Kang KJ, Shin SK, Chung SS, Lee CS: Heterotopic ossification following lumbar total disc replacement. Int Orthop 35:1197-1201, 2011

16. Shehab D, Elgazzar AH, Collier BD: Heterotopic ossification. J Nucl Med 43:346-353, 2002

17. Tortolani PJ, Cunningham BW, Eng M, McAfee PC, Holsapple GA, Adams KA: Prevalence of heterotopic ossification following total disc replacement. A prospective, randomized study of two hundred and seventy-six patients. J Bone Joint Surg Am 89:82-88, 2007

18. Whitesides TE Jr: The effect of an interspinous implant on intervertebral disc pressures. Spine (Phila Pa 1976) 28:19061907, 2003 (Letter)

19. Wilke HJ, Drumm J, Häussler K, Mack C, Steudel WI, Kettler A: Biomechanical effect of different lumbar interspinous implants on flexibility and intradiscal pressure. Eur Spine J 17: 1049-1056, 2008

20. Yi S, Kim KN, Yang MS, Yang JW, Kim H, Ha Y, et al: Difference in occurrence of heterotopic ossification according to prosthesis type in the cervical artificial disc replacement. Spine (Phila Pa 1976) 35:1556-1561, 2010

21. Yi X, McPherson B: Application of X STOP device in the treatment of lumbar spinal stenosis. Pain Physician 13:E327E336, 2010

Manuscript submitted December 11, 2012.

Accepted March 5, 2013.

Please include this information when citing this paper: DOI: 10.3171/2013.3.FOCUS12406.

Address correspondence to: Hua-Zi Xu, M.D., Zhejiang Spine Research Center, Department of Orthopaedic Surgery, Second Affiliated Hospital of Wenzhou Medical College, 109 Xueyuanxi Rd., Wenzhou 325000, China. email: spine-xu@163.com. 